\title{
Effects of diet on experimentally induced intestinal ulcers in rats: morphology and tissue leukotrienes
}

\author{
T Matsumoto, M Iida, F Kuroki, K Hizawa, H Koga, M Fujishima
}

\begin{abstract}
The effects of dietary pretreatment on longitudinal ulcers of the intestine induced by indomethacin given intracolonically were investigated in rats. The rats were pretreated with either standard diet or liquid meals. Intracolonic indomethacin $(24 \mathrm{mg} / \mathrm{kg} / \mathrm{day})$ given for two days produced longitudinal ulcers and small scattered ulcers in the small intestine in the control rats that were receiving standard pelleted formula. Three days pretreatment with one of two types of liquid meals, low residual diet (LRD) or elemental diet (ED), significantly reduced the incidence $(3 \%$ in ED group and $0 \%$ in the LRD group) and the length of the longitudinal ulcers in the small intestine. The caecum was affected in each dietary pretreatment group $(67 \%$ in controls, 80\% in LRD group, and $69 \%$ in ED group). Colonic ulcers that were located in a longitudinal fashion were found in $42 \%$ of LRD group, while these ulcers were less frequently found in the ED group (13\%) and controls $(0 \%)$. Development of ulcers in the caecum and in the colon of rats in ED and LRD groups was more delayed than that of small intestinal ulcers of control rats. In another experiment, pretreatment by ED significantly increased colonic tissue leukotriene $B_{4}$ concentration when compared with that of controls. These findings suggest that the site of experimental enteropathy induced by indomethacin given intracolonically can be modified by dietary pretreatment. This animal model can be available for investigating differences in the pathophysiology of enteropathy according to the site of involvement.

(Gut 1994; 35: 1058-1063)
\end{abstract}

Internal Medicine,

Faculty of Medicine,

Kyushu University,

Fukuoka, Japan

T Matsumoto

$M$ Iida

F Kuroki

K Hizawa

H Koga

M Fujishima

Correspondence to: Dr T Matsumoto, Second Department of Internal

Medicine, Faculty of

Medicine, Kyushu

University, Maidashi 3-1-1, Higashi-ku, Fukuoka 812, Japan.

Accepted for publication 30 November 1993 gastrointestinal damage both in humans ${ }^{1}$ and in experimental animals. ${ }^{23}$ The mechanism of these damages remains unknown, but a decrease in prostaglandins, which induce impairment of cytoprotection in the mucosa is believed to be the main cause of the lesions. ${ }^{4-6}$ There remains some controversy, however, as to whether decreased prostaglandins directly result in damages in gastrointestinal mucosa. ${ }^{7-9}$

We have previously described the effects of indomethacin when it was intracolonically given to the rat intestine, and we reported that this agent caused ulcers, predominantly in the small intestine. ${ }^{10}$ Satoh et al ${ }^{11}$ previously investigated the role of refeeding in the site of involvement within the gastrointestinal tract of the rat when indomethacin was given subcutaneously, and they found that liquid meals just before administration significantly reduced the degree of damage in the small intestine. The effect, however, of feeding both before and after treatment in the enteropathy has not been fully investigated.

In addition, based on the fact that the caecum was more frequently affected by intracolonic indomethacin in conventionally fed rats than in the previous investigations of oral or subcutaneous administration, ${ }^{10}$ we speculated that there may also be differences in the site of involvement in rats treated by this modified route of administration, according to the kind of food continuously given before and after treatment. We therefore compared the effect of solid meals and liquid meals. The liquid meals examined included both low residual type and elemental type. Both of these are commercially available and are known to be effective in the treatment of human Crohn's disease as enteral feeding. ${ }^{12}$ In addition, an attempt was made to investigate whether any correlations can be found between prefeeding and tissue leukotrienes within the intestine.

\section{Methods}

ANIMALS

Male Wistar rats (150-200 g), aged from 6 to 8 weeks, purchased from Kyushu Animal Corporation (Tosu, Saga, Japan) were used in this study. They were kept in a room with restricted access at a controlled temperature. The animals were housed in wire cages with a maximum of six animals in each cage. Standard laboratory pelleted formula and tap water were provided ad libitum, until dietary pretreatment was begun.

\section{STUDY PROTOCOL}

The animals were divided into three groups according to the dietary pretreatment. Each diet was started three days before the induction of intestinal ulcers, and was continued until the animal was killed. The animals were killed 24 , 48 , or 72 hours after the administration of indomethacin, and damage to the intestine was investigated. 
TABLE I Composition of meal used in the study

\begin{tabular}{|c|c|c|c|}
\hline & \multirow[b]{2}{*}{ Standard diet } & \multicolumn{2}{|c|}{ Liquid meal } \\
\hline & & $\begin{array}{l}\text { Low residual diet } \\
\text { (component) }\end{array}$ & $\begin{array}{l}\text { Elemental diet } \\
\text { (component) }\end{array}$ \\
\hline Protein & $18.0 \mathrm{~g} / 100 \mathrm{~g}$ & $\begin{array}{l}3 \cdot 2 \mathrm{~g} / 100 \mathrm{~g} \\
\text { (casein, soybean protein) }\end{array}$ & $\begin{array}{c}4 \cdot 2 \mathrm{~g} / 100 \mathrm{~g} \\
\text { (amino acids) }\end{array}$ \\
\hline Carbohydrate & $60.0 \mathrm{~g} / 100 \mathrm{~g}$ & $\begin{array}{l}12 \cdot 2 \mathrm{~g} / 100 \mathrm{~g} \\
\text { (dextrin, sucrose) }\end{array}$ & $\begin{array}{l}18.6 \mathrm{~g} / 100 \mathrm{~g} \\
\text { (dextrin) }\end{array}$ \\
\hline Fat & $3.0 \mathrm{~g} / 100 \mathrm{~g}$ & $\begin{array}{l}3 \cdot 2 \mathrm{~g} / 100 \mathrm{~g} \\
\text { (corn oil) }\end{array}$ & $\begin{array}{c}0.2 \mathrm{~g} / 100 \mathrm{~g} \\
\text { (soybean oil) }\end{array}$ \\
\hline Total energy & $450 \mathrm{kcal} / 100 \mathrm{~g}$ & $90 \mathrm{kcal} / 100 \mathrm{~g}$ & $88 \mathrm{kcal} / 100 \mathrm{~g}$ \\
\hline
\end{tabular}

DIET

The control rats (SD group) ingested the standard pelleted formula and tap water throughout the investigation. Liquid meal pretreated rats ingested either the elemental type (ED group) (Elental, Roussel-Morishita, Osaka, Japan) or the low residual type (LRD group) (Ensure Liquid, Dainabot, Osaka, Japan) of liquid meal, diluted homogeneously in water. Table I shows the compositions of each liquid meal. Both of the liquid meals were diluted with water $(1.0 \mathrm{kcal} / \mathrm{ml})$, and kept in a plastic bottle that permitted the animals free access. The liquid meal was freshly prepared every 24 hours. The intake of meal by the rats was confirmed by the decrease in the quantity of remaining meal. Thus, the food intake in each dietary group was assessed by total weight ingested by rats in a similar cage.

INDUCTION OF GASTROINTESTINAL DAMAGE

Indomethacin was given as described previously ${ }^{10}$ in which repeat administration uniformly produced longitudinal ulcers in the small intestine. The animals were allowed free access to food before indomethacin was given. The rats were anaesthetised with intraperitoneal sodium amobarbital $(100 \mathrm{mg} / \mathrm{kg})$. A plastic catheter measuring $6 \mathrm{~cm}$ in length was inserted rectally. Then, $24 \mathrm{mg} / \mathrm{kg}$ of indomethacin (Banyu, Tokyo, Japan) diluted in $1 \%$ of sodium carboxymethylcellulose solution (10 $\mathrm{mg} / \mathrm{kg}$ ) was injected through the catheter into the colon. Twenty four hours after the first dose, the same dose of indomethacin was again given in the same manner. To avoid coprophagy, the animals were housed in cages with raised wire mesh bases during the investigation.

\section{ASSESSMENT OF INTESTINAL LESIONS}

The rats were killed by an intraperitoneal amobarbital overdose 24,48 , or 72 hours after the second dose of indomethacin. The small intestine and the colon were removed, opened by a longitudinal incision, and pinned out on a wax block. The specimens were washed, and kept in $10 \%$ formalin for two days.

After the fixation, the specimen was investigated macroscopically. Because two types of ulceration (longitudinal ulcers and scattered small ulcers) occurred in the small intestine, they were assessed differently. A longitudinal ulcer was defined as an ulcer that was located on the mesenteric side of the intestinal lumen and measured more than $10 \mathrm{~mm}$ in longitudinal length. The total lengths of the small intestine and of the longitudinal ulcers were measured, and the longitudinal ulcer index was defined as the ratio of the length of the measured ulcers $v$ the length of the small intestine. Scattered small ulcers were defined as any ulcer smaller than $10 \mathrm{~mm}$ in its largest diameter, regardless of its location, and more than $5 \mathrm{~mm}$ distant from the longitudinal ulcers. The number of these ulcers was counted, and this figure was used as the small ulcer index.

The caecum and the colon were also examined. The largest diameter of those caecal ulcers that measured more than $5 \mathrm{~mm}$ in diameter, and the number of ulcers smaller than $5 \mathrm{~mm}$ both in the colon and the caecum were recorded.

\section{SERUM INDOMETHACIN CONCENTRATION}

In rats that were killed 24 hours after the second administration of indomethacin, blood samples were obtained from the inferior vena cava. These blood samples were centrifuged, and the serum concentrations of indomethacin were measured by high performance liquid chromatography.

\section{TISSUE LEUKOTRIENES $\mathrm{B}_{4}$ AND $\mathrm{C}_{4}$} MEASUREMENT

In another experiment, tissue samples of the small intestine, the caecum, and the colon were obtained from the animals for the measurement of leukotrienes $\mathrm{B}_{4}\left(\mathrm{LTB}_{4}\right)$ and $\mathrm{C}_{4}\left(\mathrm{LTC}_{4}\right)$ before the induction of gastrointestinal damage. Samples of the small intestine were obtained from the upper jejunum (10 cm from the pylorus), from just the middle of the small intestine, and from the lower ileum $(10 \mathrm{~cm}$ from the ileocaecal junction). The measurements were made 48 hours after each dietary pretreatment was started. Immediately after the animals were killed by amobarbitrate overdose, tissue samples were obtained, washed with saline, and kept in a refrigerator at $-80^{\circ} \mathrm{C}$. These samples were later weighed, finely minced with scissors, suspended in $1.0 \mathrm{ml}$ of $20 \mathrm{mM}$ TRIS buffer, and incubated in a water bath for 20 minutes. The samples were then centrifuged for 30 seconds and the supernatant was processed for the subsequent measurements of $\mathrm{LTB}_{4}$ and $\mathrm{LTC}_{4}$ using the commercial $\left[{ }^{3} \mathrm{H}\right]$ radioimmune $\mathrm{LTB}_{4}$ and $\mathrm{LTC}_{4}$ assay (TRK, 910; Asherman Research Corporation, Arlington Heights, IL).

\section{STATISTICAL ANALYSES}

The incidence of intestinal damage was compared using the $\chi^{2}$ test. Parametric data were expressed as mean (SEM), and the values were compared among the groups, using one way analysis of variance (ANOVA). A p value $<0.05$ was considered significant. 


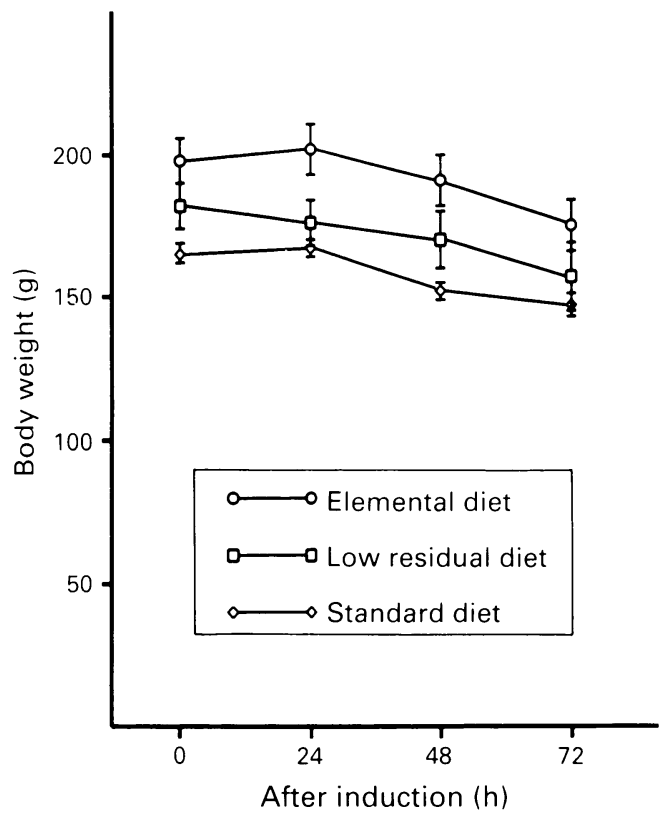

Figure 1: Serial changes in body weight within the standard diet (SD) group, the elemental diet (ED) group, and the low residual diet (LRD) group.

\section{Results}

GENERAL FINDINGS

The rats constantly ingested each type of food both before and after the induction of gastrointestinal damage. The average food intake before indomethacin was $10.2 \mathrm{~g} /$ day/rat $(45.9$ $\mathrm{kcal} / \mathrm{day} / \mathrm{rat}$ ) in the SD group, $44 \mathrm{~g} /$ day $/ \mathrm{rat}$ (39.6 $\mathrm{kcal} / \mathrm{day} / \mathrm{rat})$ in the LRD group, and $42 \mathrm{~g} / \mathrm{day} / \mathrm{rat}(40.0 \mathrm{kcal} / \mathrm{day} / \mathrm{rat})$ in the $\mathrm{ED}$

TABI II Site and incidence of involiement for each diet group

\begin{tabular}{|c|c|c|c|c|}
\hline \multicolumn{5}{|c|}{ Sinall intestime } \\
\hline & Lomginudinal ulcer & Sinall ulcer & Caccum & Colon \\
\hline SD group $(n-24)$ & $24 / 24(100 \%) \dagger$ & $10 / 24(420 / 11)$ & $16 / 24(67 \%)$ & $0 / 24(01111)^{\star}$ \\
\hline ED group $(n=30)$ & $1 / 30(3 \%) t$ & $13 / 30\left(43^{\prime \prime \prime)}\right)$ & $24 / 30(80 \%)$ & $4 / 30(13 \%)^{\star}$ \\
\hline I.RI) group $(n=26)$ & $0 / 26(0 \%) \dagger$ & $11 / 26(42 \%)$ & $18 / 26(69 \%)$ & $11 / 26(42 \%)^{*}$ \\
\hline
\end{tabular}

$\mathrm{SD}=$ standard diet $; \mathrm{ED}=\mathrm{elemental}$ diet $\mathrm{I} . \mathrm{RD}=\mathrm{low}$ residual diet. ${ }^{\star} \mathrm{p}<0.005,+\mathrm{p}<0.001$.

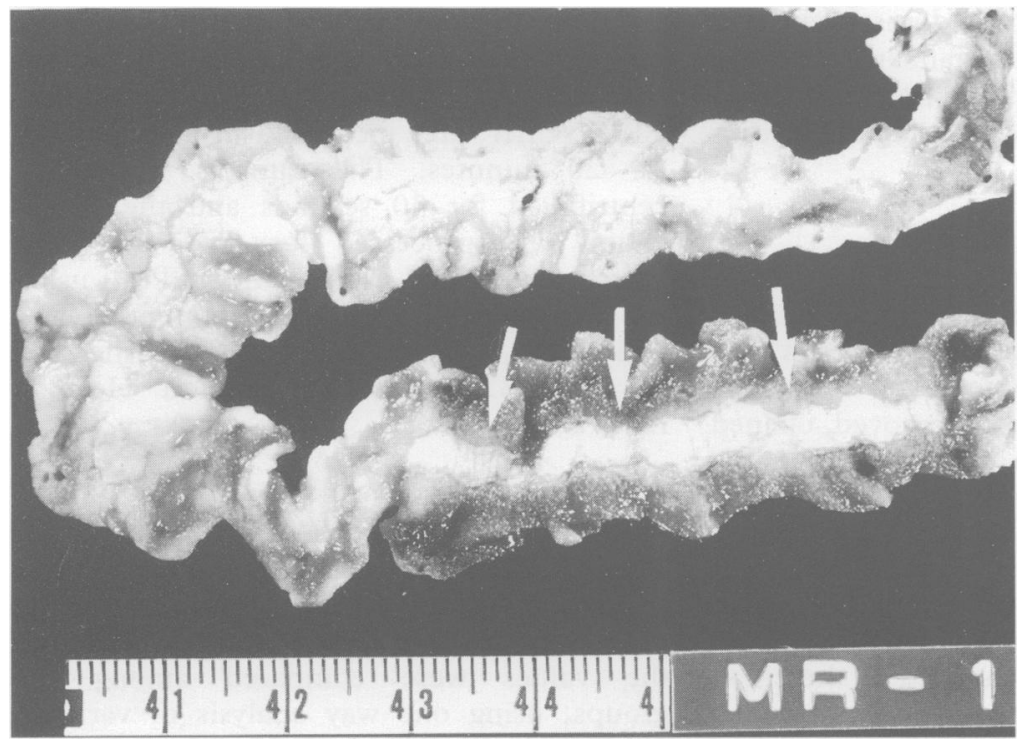

Figure 2: Typical longitudinal ulcer seen in the middle small intestine of a rat in the SD group (arrows). The ulcer was located in the mesenteric side of the small intestine. group. The rats in each diet group commonly manifested diarrhoea after indomethacin. The food intake decreased to $4.2 \mathrm{~g} / \mathrm{day} / \mathrm{rat}$ $(18.9 \mathrm{~g} /$ day $/ \mathrm{rat}$ ) in $\mathrm{SD}$ group, $19 \mathrm{~g} /$ day $/ \mathrm{rat}$ $(17 \cdot 1 \mathrm{kcal} / \mathrm{day} / \mathrm{rat})$ in the LRD group, and $18 \mathrm{~g} /$ day $/ \mathrm{rat}(15.8 \mathrm{kcal} /$ day/rat $)$ in the ED group. As Fig 1 shows, the body weight of the rats gradually decreased in each diet group. There were no significant differences in the decrease of body weight between the three groups. The serum concentration of indomethacin 24 hours after the second dose was not different among the groups $(14 \cdot 3(5 \cdot 3)$ $\mu \mathrm{g} / \mathrm{m}$ in the SD group $(\mathrm{n}=8), 12 \cdot 6(4 \cdot 8) \mu \mathrm{g} / \mathrm{ml}$ in the ED group $(n=8)$, and $13 \cdot 8(4 \cdot 5) \mu \mathrm{g} / \mathrm{ml}$ in the LRD group $(n=8)$ ).

SMALI INTESTINAL DAMAGE

While the small intestine was affected by longitudinal ulcers on the mesenteric side of the lumen in rats in the SD group (Fig 2), this type of ulcer was less frequently found in the ED and LRD groups. The incidence was lower in both the LRD group $(0 \%, \mathrm{p}<0.001)$ and the ED group $(3 \%, \mathrm{p}<0.001)$ than in the $\mathrm{SD}$ group $(100 \%)$ (Table II). These differences in the incidence of longitudinal ulcers were seen at 24, 48 and 72 hours after induction (Fig 3). In contrast with the longitudinal ulcers, small scattered ulcers were found in each diet group. While the incidence of these small ulcers was
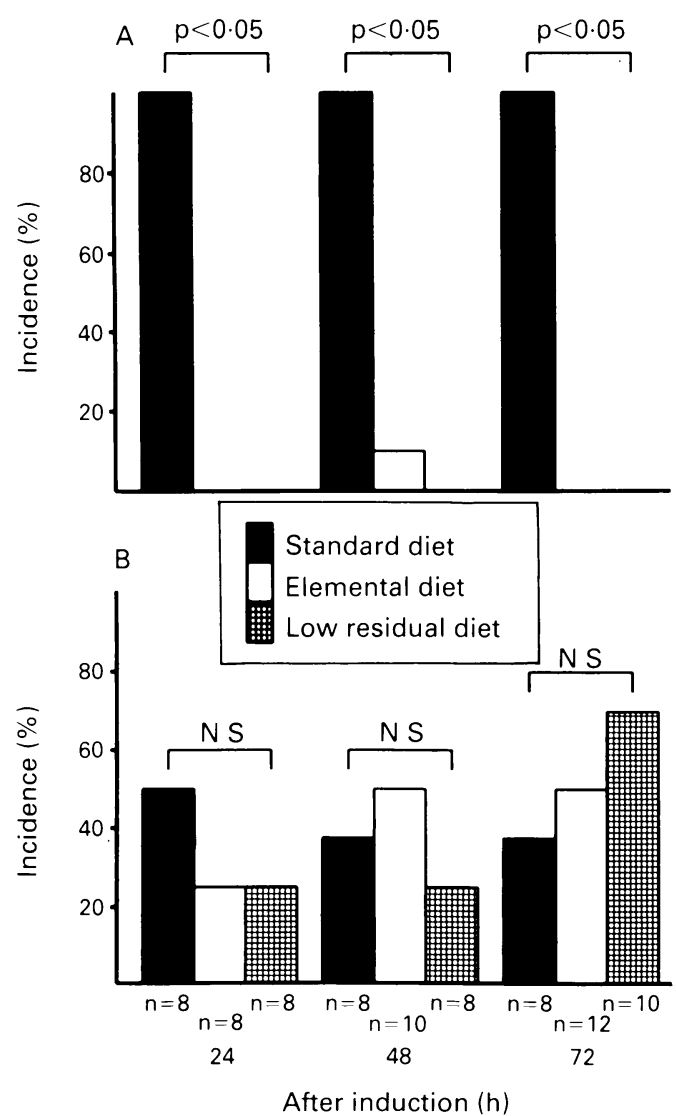

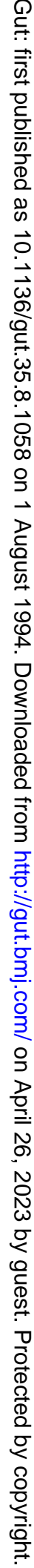

Figure 3: Incidence of longitudinal ulcers $(A)$ and small ulcers $(B)$ of the small intestine within the three diet groups. The incidence of longitudinal was significantly higher in the SD group than in the SD and LRD groups at 24,48 , and 72 hours after indomethacin. Although the incidence of small ulcers was similar among the groups, it gradually, increased in the LRD group. 


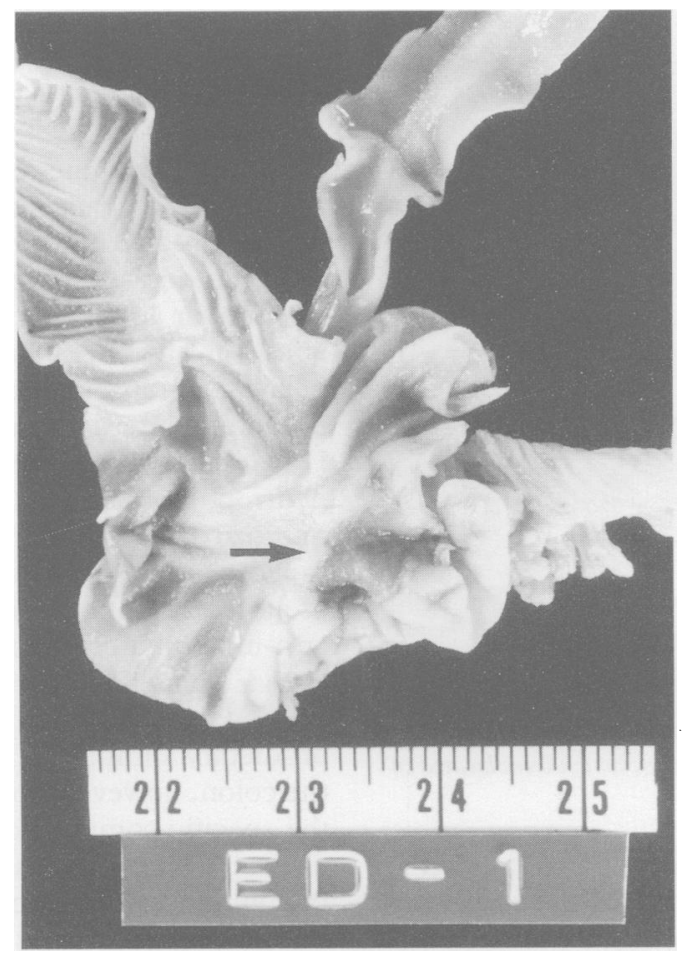

Figure 4: $A$ large caecal ulcer seen in a rat belonging to the ED group (arrow).

not different between the three groups (Table II and Fig 3), the number of ulcers was less in the ED group (4(2)/rat) and in the LRD group $(4(3) /$ rat $)$ than in the $\mathrm{SD}$ group $(9(3) / \mathrm{rat}$, $\mathrm{p}<0.05)$.

\section{CAECAL AND LARGE INTESTINAL DAMAGE}

The caecum was frequently affected in rats ingesting LRD or ED. While the caecal damage in rats in the SD group was characterised by small ulcers measuring less than $5 \mathrm{~mm}$ in diameter, the caecum of rats in the LRD group or in the ED group was more severely damaged by round or irregular ulcers that measured more than $5 \mathrm{~mm}$ in diameter, and the whole thickness of the caecal wall was severely inflamed (Fig 4). While caecal ulcers

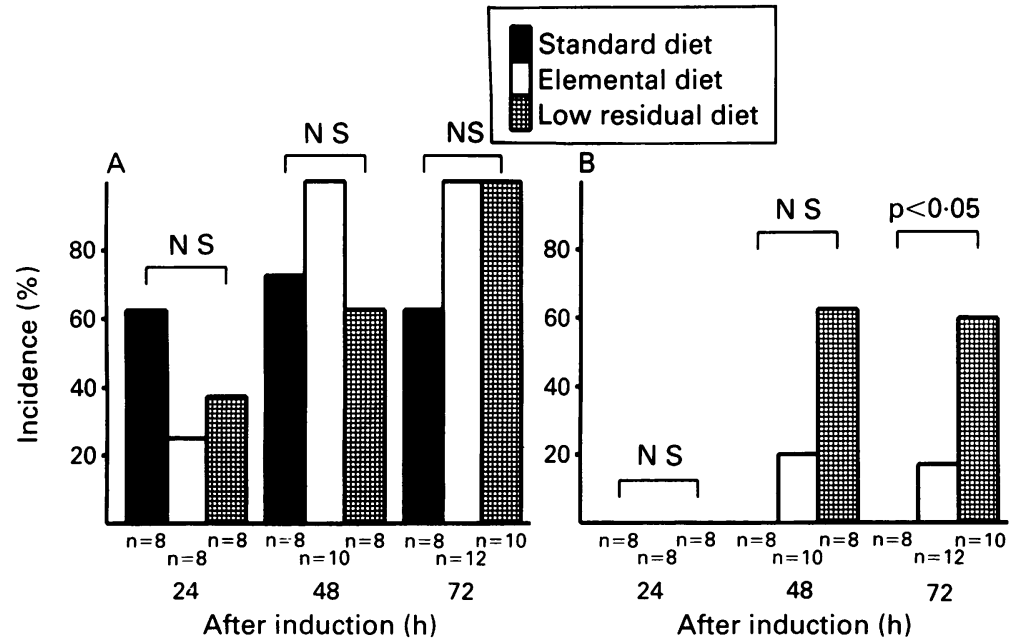

Figure 5: Comparison of the incidence of caecal (A) and colonic ulcers (B) among the three groups. While caecal ulcers developed less frequently in both the ED and LRD groups 24 hours after indomethacin, the incidence gradually increased. Similarly, colonic ulcers developed 48 and 72 hours after indomethacin in the LRD group, while these ulcers were less frequently seen in the ED group. Colonic ulcers were not seen in the SD group. developed within 24 hours in the SD group, the ulcer tended to develop later in the ED group and LRD group (Figure 5).

The colon of rats in the LRD group and in the ED group was frequently affected by small ulcers, whereas these colonic ulcers was not seen in the SD group. The incidence of colonic ulcers was higher in the LRD group than in the ED group (63\% in the LRD group $v 20 \%$ in the ED group after 48 hours, and $60 \%$ in the LRD group $v 17 \%$ in the $\mathrm{ED}$ group after 72 hours) (Fig 5). The ulcers were located in a longitudinal fashion in the LRD group (Fig 6). The number of the colonic ulcers, however, was not significantly different between the ED group (5(4)/rat) and the LRD group (6(4)/rat).

TISSUE LEUKOTRIENES $\mathrm{B}_{4}$ AND $\mathrm{C}_{4}$

Figure 7 shows the tissue concentrations of $\mathrm{LTB}_{4}$ and $\mathrm{LTC}_{4}$ in rats pretreated by either SD, ED, or LRD for 48 hours. Six rats were investigated in each group. While tissue $\mathrm{LTC}_{4}$ was not different among the groups at any site of the intestine, tissue $\mathrm{LTB}_{4}$ was statistically higher in the ED group than in the $\mathrm{SD}$ or LRD group. In particular, $\mathrm{LTB}_{4}$ of the caecum $(1 \cdot 68(0 \cdot 16) \mathrm{pg} / \mathrm{mg}$ and the colon $(6 \cdot 22(0 \cdot 64) \mathrm{pg} / \mathrm{mg})$ in the ED group was higher than those in the SD group $(0 \cdot 38(0.05) \mathrm{pg} / \mathrm{mg}$ and $0.55(0.05) \mathrm{pg} / \mathrm{mg}$ and in the LRD group $(0 \cdot 12(0 \cdot 04) \mathrm{pg} / \mathrm{mg}$ and $0 \cdot 13(0 \cdot 04) \mathrm{pg} / \mathrm{mg})$.

\section{Discussion}

Since the original description of indomethacin induced enteropathy in experimental animals, ${ }^{2} 3$ some investigators have shown that low residual diet significantly prevents these lesions, ${ }^{1113}$ and they therefore speculated that the solid components of a diet may play an important part in the pathogenesis of experimental enteropathy induced by this drug. In the investigation by Satoh et al, ${ }^{11}$ one hour of refeeding by liquid meal just before the subcutaneous administration of indomethacin obviously prevented the small intestinal lesions.

In this study, we expanded the time of dietary pretreatment, and in addition, further investigated the possible role of long periods of refeeding in the pathogenesis of indomethacin induced enteropathy. Because repeat intracolonic administration of indomethacin predominantly produces longitudinal ulcers, ${ }^{10}$ even in rats ingesting standard diet the numbers of small ulcers were comparatively small when compared with previous reports. ${ }^{2-4}$

Both ED and LRD significantly reduced the incidence of longitudinal ulcers of the small intestine, which have always been found in rats pretreated by the standard diet, and fewer small ulcers were seen in the small intestine. There may be a possibility that a difference in enterohepatic circulation of indomethacin ${ }^{3}$ among the dietary groups resulted in differences in the incidence of small intestinal lesions. Because the food intake after indomethacin was not, however, obviously different among the groups, our 


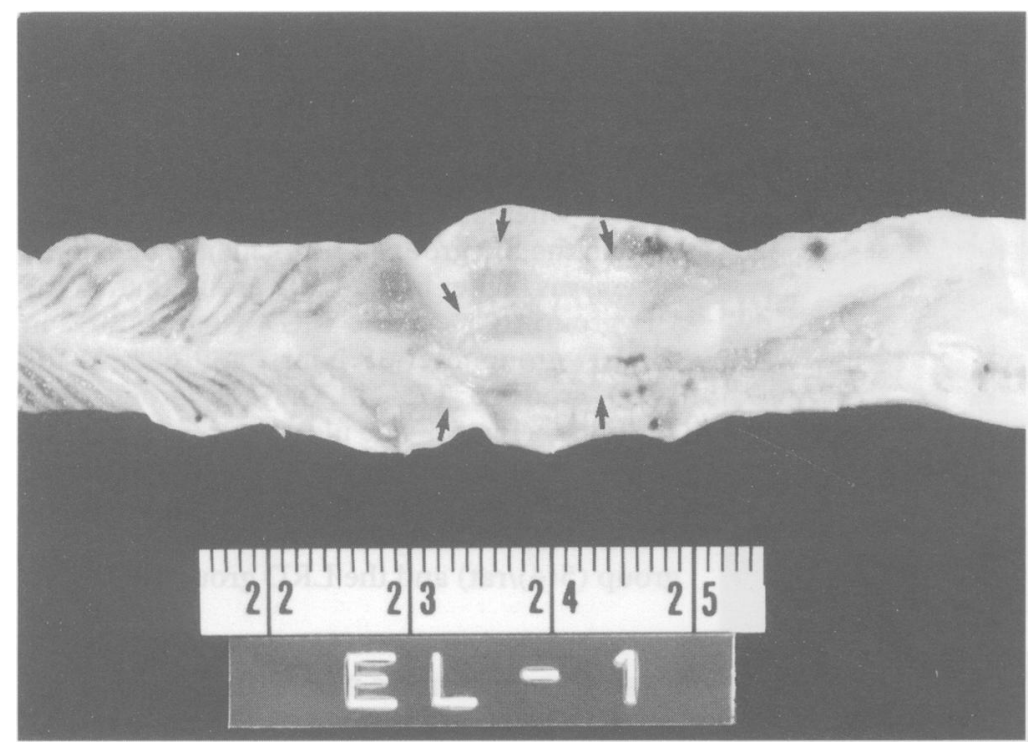

Figure 6: Colonic ulcers in a rat from the LRD group. Small ulcers, which were located in a longitudinal fashion in three lines can be seen (arrows).

findings suggest that even in rats treated by intracolonic indomethacin, solid components of diet before and after treatment play an important part in the pathogenesis of enteropathies in the small intestine.

In contrast with the small intestine, the caecum and the colon of rats ingesting liquid meals were frequently affected by small ulcers. These colonic lesions were not seen in any of the rats treated by standard diet as confirmed by the previous investigation by Ligumsky et al. ${ }^{14}$ The development of colonic damage in the liquid diet groups may be partly explained
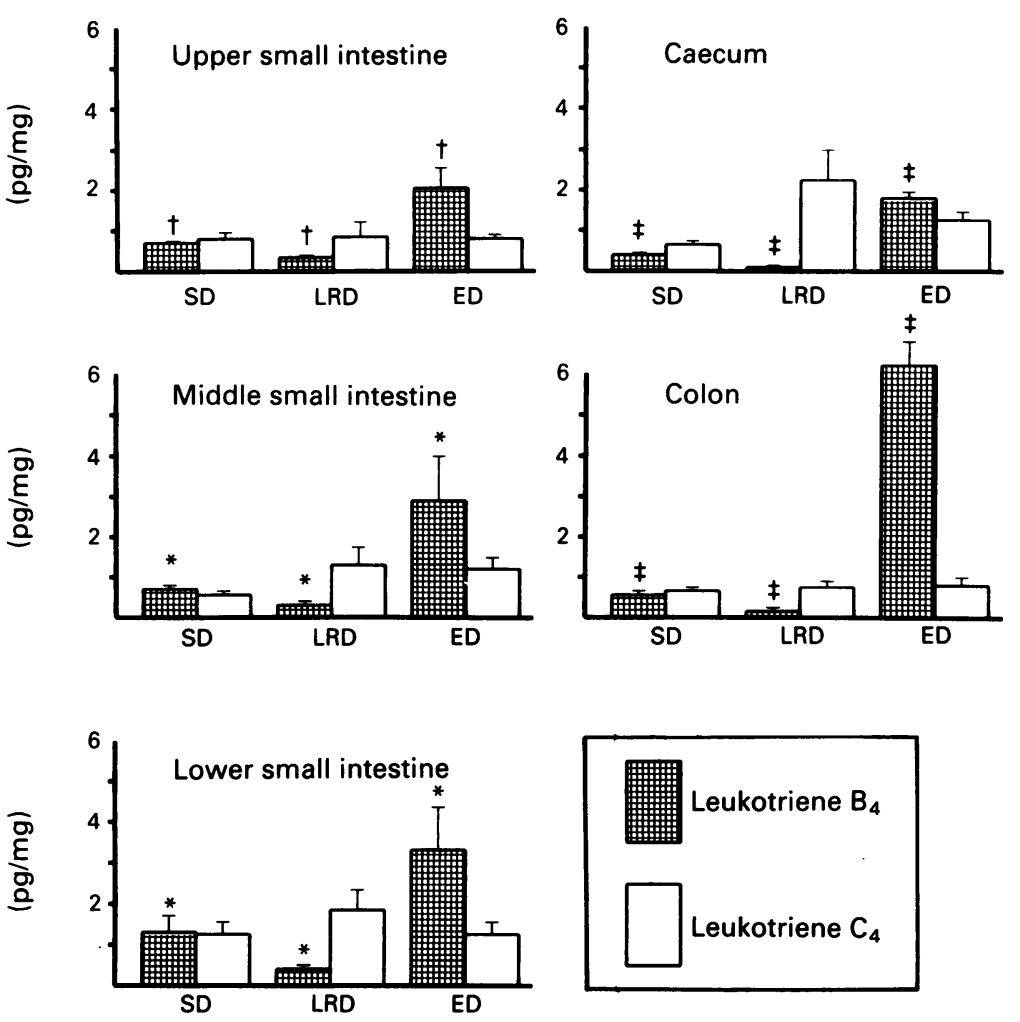

Figure 7: Effects of pretreatment by $S D, E D$, and LRD on tissue leukotrienes $B_{4}\left(L T B_{4}\right)$ and $C_{4}\left(L T C_{4}\right)$. Each group consisted of six animals, and results are expressed as mean (SEM). While LTC 4 was not different among $S D, L R D$, and $E D$ groups, $L T B_{4}$ was significantly different among the groups by one way analysis of variance. ${ }^{\star} p<0.05$, $\dagger p<0.005, \ddagger p<0.001$. by the colonic administration of indomethacin applied in this study. Indomethacin may have directly damaged the colon, which contained less faeces because of the liquid meal pretreatment. Because the colonic ulcers (and also scattered small ulcers of the small intestine) occurred later, however, in the liquid diet groups, and as the food intake after treatment was similar among the groups, it seems reasonable to attribute the occurrence of these delayed lesions to the continuous feeding of liquid diet after indomethacin.

It has been recently reported that neutrophil-endothelial interaction ${ }^{15-17}$ and microcirculatory disturbances ${ }^{18}$ within the mucosa are the initial step in the pathogenesis of gastroenteropathy induced by non-steroidal anti-inflammatory drugs. In our experiment, both ED and LRD are considered to have suppressed the subsequent bacterial invasion 25619 or dietary stimuli ${ }^{11} 13$ in the small intestine. In the colon, however, the continuous stream and the specific composition of diarrhoea, but not the solid faeces or bacteria, seems the factor that enhances the mucosal damages.

The liquid meals used in this study have been known to change epithelial cell proliferation in the rat small intestine or in the colon. ${ }^{20-24}$ Maxton et $a^{20}$ reported that elemental diet and complete liquid meals induced atrophy in the terminal ileum of rats. In other experiments, ${ }^{21} 2224$ atrophy in the colonic mucosa induced by elemental diet has been confirmed. Thus, the difference in the frequency of colonic involvement between the ED and LRD groups in this study can be explained by the difference in the degree of proliferative activity within the colonic mucosa both before and after indomethacin treatment, which has been recently confirmed to accelerate cell losses from the epithelial surfaces. ${ }^{25}$

The role of increased leukotrienes in the pathogenesis of experimental colitis induced by acetic acid ${ }^{26}$ and trinitrobenzene sulphonic acid $^{27-29}$ has been described. Although we evaluated tissue $\mathrm{LTB}_{4}$ and $\mathrm{LTC}_{4}$ in consideration of possible correlation between these metabolites and dietary pretreatment, we failed to obtain any conclusive data that can explain the difference in the site of enteropathy. Our results suggest, however, the possibility that diet pretreatment changes tissue concentrations of these metabolites. Further studies seem necessary from this point of view.

This study confirmed that intracolonic administration of indomethacin induced small intestinal ulcers in conventionally fed rats, while liquid meals significantly reduced the incidence of such ulcers. In addition, whereas treatment by the low residual type of liquid meal resulted in the occurrence of colonic ulcers, such damage was less frequently seen in rats ingesting the elemental diet. These findings partly conform to the clinical responses to liquid meals seen in human patients with Crohn's disease. ${ }^{12} 30$ While indomethacin induced enteropathy in experimental animals seems unavailable for grading human Crohn's disease, our results suggest that the rat model of colonic ulcers 
can be intentionally produced by a method that includes dietary pretreatment. This may contribute to the understanding of the difference in pathophysiology of enteropathy within the intestine.

This study was supported in part by the intractable disease committee, the Japanese Ministry of Health and Welfare.

1 Bjarnason I, Zanelli G, Smith T, Prouse P, Williams P, Smethurst $\mathrm{P}$, et al. Nonsteroidal antiinflammatory drug-induced intestinal inflammation in humans. Grug-induced intestinal inflamm

2 Kent TH, Cardelli RM, Stamler FW. Small intestinal ulcers and intestinal flora in rats given indomethacin. $A m \mathcal{F}$ and intestinal flora in rats

3 Brodie DA, Cook PG, Bauer BJ, Dagle GE. Indomethacininduced intestinal lesions in the rat. Toxicol Appl Pharmacol 1970; 17: 615-24.

4 Fang WF, Broughton A, Jacobson ED. Indomethacininduced intestinal inflammation. Dig Dis 1977; 22: 749-60.

5 Robert A. An intestinal disease produced experimentally by a prostaglandin deficiency. Gastroenterology 1975; 69: 1045-7.

6 Robert A, Asano T. Resistance of germfree rats to indomethacin-induced intestinal lesions. Prostaglandins 1977; 14: 333-41.

7 Whittle BJR. Temporal relationship between cyclo-oxygenase inhibition, as measured by prostacyclin biosynthesis, and the gastrointestinal damage induced by indomethacin in the rat. Gastroenterology 1981; 80: 94-8.

8 Petokas S, Nandi J, Enthoven D. Effects of nonsteroidal anti-inflammatory drugs on gastrointestinal injury and prostanoid generation in healthy volunteers. Dig Dis $S c$ 1988; 33: 660-6.

9 Ligumski M, Golanska EM, Hansen DG, Kauffman GL. Aspirin can inhibit gastric mucosal cyco-oxygenase without causing lesions in the rat. Gastroenterology 1983; 84: 756-61.

10 Matsumoto T, Iida M, Nakamura S, Kuroki F, Hizawa K Fujishima $M$. An animal model of longitudinal ulcers in the small intestine induced by intracolonically administhe small intestine induced by intracolonically administered

11 Satoh H, Guth PH, Grossman MI. Role of food in gastrointestinal ulceration produced by indomethacin in the rat. Gastroenterology 1982; 83: 210-5.

12 Raouf AH, Hildrey V, Daniel J, Walker RJ, Krasner N, Elia $\mathrm{E}$, et al. Enteral feeding as sole treatment for Crohn's disease: controlled trial of whole protein $\mathrm{v}$ amino acid based feed and a case study of dietary challenge. Gut 1991; 32: 702-7.

13 Dress DT, Robbins TL, Cargo FL. Effect of low-residue foods on indomethacin-induced intestinal lesions in rats. Toxicol Appl Pharmacol 1974; 27: 194-9.
14 Ligumsky M, Sestieri M, Karmeli F, Zimmerman J, Okon E, Rachmilewitz D. Rectal administration of nonsteroidal antiinflammatory drugs. Gastroenterology 1990; 98: 1245-9.

15 Wallace JL, Keenan CM, Granger DN. Gastric ulceration induced by non-steroidal anti-inflammatory drugs is a neutrophil-dependent process. Am f Physiol 1990; 259: G462-7.

16 Wallace JL, Arfors KE, McKnight GW. A monoclonal antibody against the $\mathrm{CD} 18$ leukocyte adhesion molecule prevents indomethacin-induced gastric damage in the rabbit. Gastroenterology 1991; 100: 878-83.

17 Trevethick MA, Clayton NM, Strong P, Harman IW. Do infiltrating neutrophils contribute to the pathogenesis of indomethacin induced ulceration of the rat gastric antrum. Gut 1993; 34: 156-60.

18 Miura S, Suematsu M, Tanaka S, Nagata H, Houzawa $S$, Suzuki $M$, et al. Microcirculatory disturbance in Suzuki M, et al. Microcirculatory disturbance in
indomethacin-induced intestinal ulcer. Am $\mathcal{f}$ Physiol 1991; 261: G213-9.

19 Satoh H, Guth PH, Grossman MI. Role of bacteria in gastric ulceration produced by indomethacin in the rat. Cytoprotective actions of antibiotics. Gastroenterology 1983; 84: 483-9.

20 Maxton DG, Cynk EU, Thompson RPH. Small intestinal response to 'elemental' and 'complete' liquid feeds in the rat: effect of dietary bulk. Gut 1987; 28: 688-93.

21 Morin CL, Ling V, Bourassa D. Small intestinal and colonic changes induced by a chemically defined diet. Dig Dis $\mathrm{Sci}$ 1980; 25: 123-8.

22 Janne P, Carpentier Y, Willems G. Colonic mucosal atrophy induced by a liquid elemental diet in rats. Dig Dis atrophy induced by a

23 Ecknauer R, Sircar B, Johnson LR. Effect of dietary bulk on small intestinal morphology and cell renewal in the rat. small intestinal morphology and
Gastroenterology 1981;81: 781-6.

24 Storme G, Willems G. The effect of a liquid elemental diet on cell proliferation in the colon of rats. Cell Tissue Res 1981; 216: 221-5.

25 Uribe A. Indomethacin accelerates clearance of labeled cells and increases DNA synthesis in gastrointestinal mucosa of the rat. Dig Dis Sci 1992; 37: 403-8.

26 Zipser RD, Nast CC, Lee M, Kao HW, Duke R. In vivo production of leukotriene $\mathrm{B}_{4}$ and leukotriene $\mathrm{C}_{4}$ in rabbit colitis: relationship to inflammation. Gastroenterology 1987; 92: 33-9.

27 Rachmilewitz D, Simon PL, Schwartz LW, Griswold DE, Fondacaro JD, Wasserman MA. Inflammatory mediators Fondacaro JD, Wasserman MA. Inflammatory mediators of experim

28 Wallace JL, MacNaughton WK, Morris GP, Beck PL. Inhibition of leukotriene synthesis markedly accelerates healing in a rat model of inflammatory bowel disease. Gastroenterology 1989; 96: 29-36.

29 Wallace JL, Keenan CM. Leukotriene $\mathrm{B}_{4}$ potentiates colon ulceration in the rat. Dig Dis Sci 1990; 35: 622-9.

30 Park RHR, Galloway A, Danesh BJZ, Russell RI. Double blind trial comparing elemental polymeric diet as primary therapy for active Crohn's disease. Gut 1989; 30: A1453. 